Document downloaded from:

http://hdl.handle.net/10251/160092

This paper must be cited as:

Martinez-Ferri, JE.; Juste Vidal, BJ.; Verdú Martín, GJ.; Miró Herrero, R.; Ortiz Moragón, J.; Martorell Alsina, SS. (2019). Developing a novelty method to estimate Radon doses in a Waste Water pre-Treatment Plant. Radiation Physics and Chemistry. 155:323-327. https://doi.org/10.1016/j.radphyschem.2018.09.009

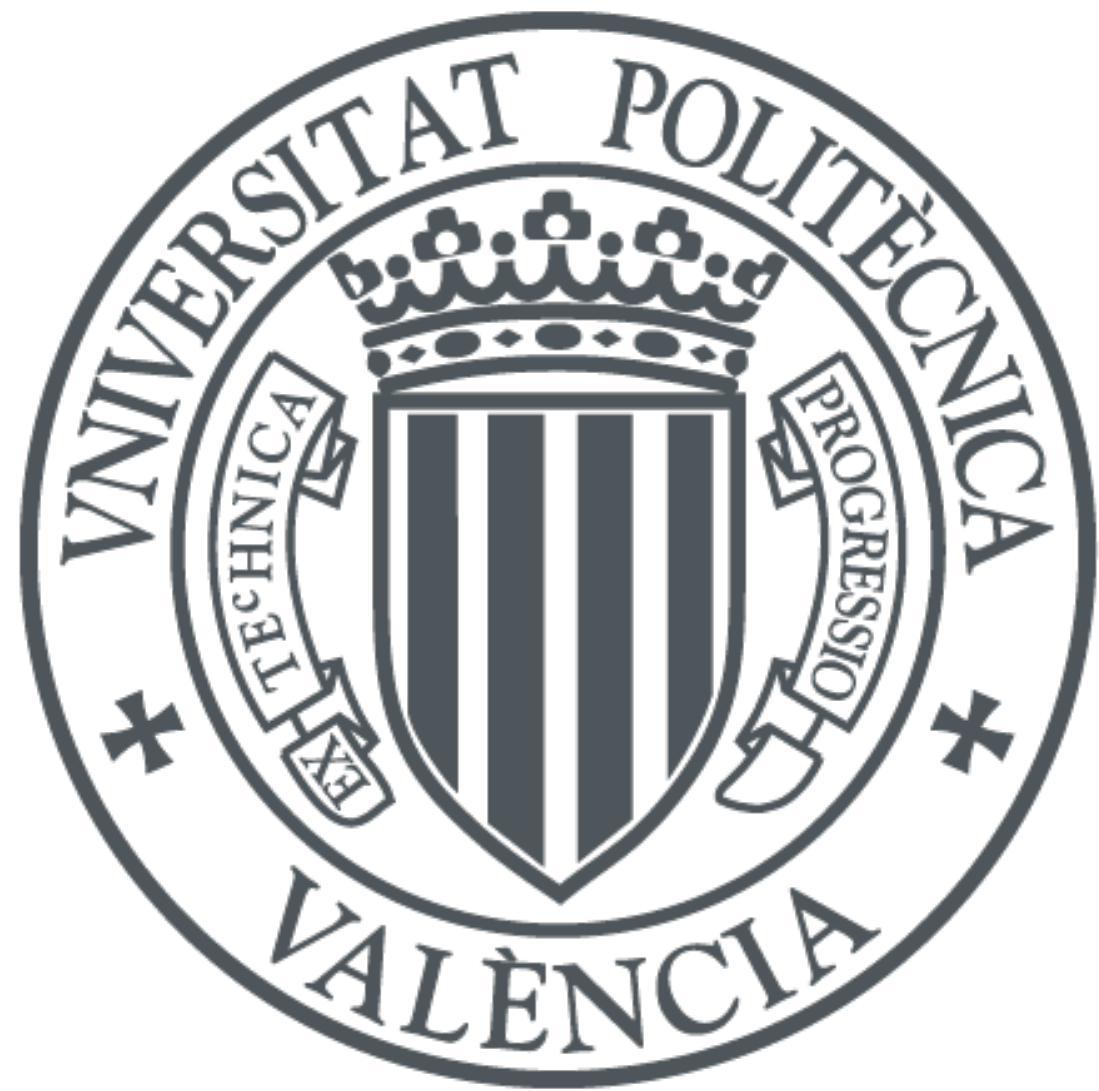

The final publication is available at

https://doi.org/10.1016/j.radphyschem.2018.09.009

Copyright Elsevier

Additional Information 


\title{
Developing a novelty method to estimate Radon doses in a Waste Water pre-Treatment Plant
}

\author{
J.E. Martinez ${ }^{1}$, B. Juste ${ }^{1}$, G. Verdu ${ }^{1}$, R. Miró ${ }^{1}, J$. Ortiz $^{2}$, S. Martorell ${ }^{2}$ \\ (1) Instituto de Seguridad Industrial, Radiofísica y Medioambiental (ISIRYM).Universitat Politècnica de \\ València, Camí de Vera s/n. 46022, Spain \\ (2) Laboratorio de Radioactividad Ambiental. Universitat Politècnica de València, Camí de Vera s/n. \\ 46022, Spain
}

Keywords: Radon, Equilibrium Factor, Waste Water, Inhalation Doses, Lung Dosimetry, Compartment models, Radon descendents.

\begin{abstract}
According to World Health Organization (WHO), the radon is the second leading cause of lung cancer. This work is centered on a Waste Water Pre-Treatment Plant (WWTP) with radon concentration above Spanish action level (600 Becquerel per cubic meter). The authors have developed a novelty method based on gamma and alpha spectrometry to measure the radon equilibrium factor. At the same time, a Matlab@ algorithm (UPVDose) has been coded based on the International Commission on Radiological Protection (ICRP) 66 Human Respiratory Tract Model for Radiological Protection (HRT), to calculate the inhalation doses received by workers of this treatment plant due to the radon progeny. The effective doses of the workers obtained in the human respiratory tract are found to be low, but results are very dependent on the radionuclide type of absorption.
\end{abstract}

\section{Introduction}

The radon equilibrium factor $(F)$ shows the degree of balance between radon and its short-lived progenies. It is difficult to measure directly the concentration of these decay products. ICRP 65 (ICRP, 1993) suggests a rounded value for the equilibrium factor of 0.4 for indoor environments. This estimated value may vary in different situations since it is influenced by environmental factors such as pressure, temperature or humidity. To obtain a precise dose calculation caused by radon and its progeny, it is necessary to know the value of the equilibrium factor in each case. The measurement in our case was made using a simultaneous sampling of air through a filter paper and alpha spectrometry measurement of radon activity concentration in the air. The filter paper was measured a posteriori in a gamma spectrometer. In parallel, an algorithm was developed in Matlab@ (UPVDose), using the symbolic package. This algorithm represents the human respiratory tract according to the ICRP 66 (ICRP, 1994) recommendations. Once the equilibrium factor was obtained the concentrations in air for each of the radon's progeny Po-218, Pb-214 and Bi-214 was determined. With these concentrations, the effective dose in the human respiratory tract was computed for each progeny. To that, the developed algorithm (UPVDose) was used.

The authors analyze in this work a Waste Water Pre-Treatment Plant (WWTP) located at the Mediterranean coast with air radon concentration above Spanish action level. This paper presents a method for radon equilibrium factor determination in order to estimate WWTP workers effective dose more exactly.

The outline of the paper is as follows. The experimental measures procedure is explained in section 2 . Section 3 is dedicated to materials and methodology. In section 4 is presented the results and validation. Finally, section 5 summarizes the major conclusions of this work.

\section{Experimental measures procedure}

Measurement procedure had two different parts; measures taken in-situ at the treatment plant, and the others corresponding to the sampling process and analysis carried out at the "Environmental Radioactive Laboratory" at the Polytechnic University of Valencia (Valencia).

At the treatment plant two measures were undertaken. On the one part, radon activity concentration was measured during two days by a continuous radon measuring instrument based on alpha spectrometer (RAD7 ${ }^{\circledR}$, Durridge Company) (Durridge, 2015). RAD7 ${ }^{\circledR}$ detector is based on electrostatic collection of alpha-emitters with spectral analysis using a passivated Ion-implanted Planar Silicon detector that converts 
alpha radiation directly to an electrical signal. One important advantage of solid state detectors is their ability to electronically determine the energy of alpha particle.

On the other hand, air suction was done using an air sampler F\&J DF-14ME with fiberglass filter paper of $\varepsilon=98 \%$ efficiency was used for aerosol sampling. The pump flow velocity was $v=1 \mathrm{e}^{-3} \mathrm{~m}^{3} / \mathrm{s}(60 \mathrm{~L} / \mathrm{min})$. Radon short lived daughters attached to aerosols were collected on the fixed filter paper.

The filter was analyzed at the laboratory by gamma spectrometry performed in an Ortec GMX 40 Germanium detector, with extended range from $6 \mathrm{keV}$ to $3 \mathrm{MeV}$, a $2 \mathrm{keV}$ resolution and placed in original lead shield with wall thickness of $10 \mathrm{~cm}$.

\section{Materials and methodology}

\subsection{Equilibrium factor}

The below diagram shows the process steps: sampling (graph in red), transport and measurement (graph in blue). The first step corresponds to the air suction with the pump, the second step is centered on the transport of the sampling to the laboratory and the filter measurement with the gamma spectrometer.
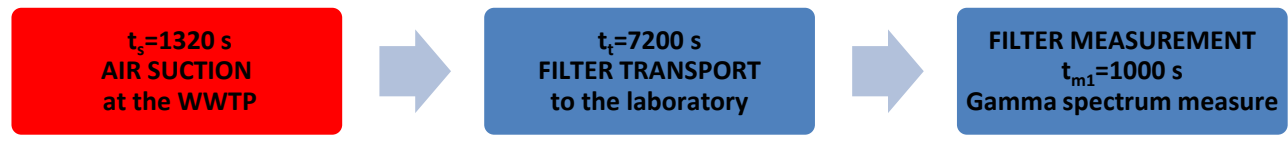

Figure 1. Temporal diagram.

As described before, the analysis of the radon decay products fixed at the fiberglass filter paper can be studied in two different steps.

The dynamic equations during air suction (the first sampling part at the WWTP) are given by equations Eqs. $(1,2,3)$. And their initial conditions are $N_{P o}(0)=0, N_{P b}(0)=0$ and $N_{B i}(0)=0$. The air suction duration was $t_{s}=1320 \mathrm{~s}$.

$$
\begin{aligned}
\frac{d N_{P o}}{d t_{R}} & =C_{P o} v \varepsilon-\lambda_{P o} N_{P o} \\
\frac{d N_{P b}}{d t_{R}} & =C_{P b} v \varepsilon+\lambda_{P o} N_{P o}-\lambda_{P b} N_{P b} \\
\frac{d N_{B i}}{d t_{R}} & =C_{B i} v \varepsilon+\lambda_{P b} N_{P b}-\lambda_{B i} N_{B i}
\end{aligned}
$$

While the dynamics equations in the second part (corresponding to the filter transport and laboratory analysis) are given by Eqs. $(4,5,6)$. Their initial conditions are $N^{\prime}{ }_{P o}(0)=N_{P o}\left(t_{s}\right), N^{\prime}{ }_{P b}(0)=N_{P b}\left(t_{s}\right)$ and $N^{\prime}{ }_{B i}(0)=N_{B i}\left(t_{s}\right)$. The filter transport duration from the WWTP to the laboratory is $t_{t}=7200 \mathrm{~s}$. At the laboratory a measure of $t_{m}=1000 \mathrm{~s}$ was carried out $\left(t_{l}\right)$.

$$
\begin{gathered}
\frac{d N_{P o}^{\prime}}{d t}=-\lambda_{P o} N_{P o}^{\prime} \quad(4) \\
\frac{d N_{P b}^{\prime}}{d t}=\lambda_{P o} N_{P o}^{\prime}-\lambda_{P b} N_{P b}^{\prime} \\
\frac{d N_{B i}^{\prime}}{d t}=\lambda_{P b} N_{P b}^{\prime}-\lambda_{B i} N_{B i}^{\prime}
\end{gathered}
$$

The number of decayed nuclei of $\mathrm{Pb}-214$ and Bi-214 during the measurement $\left(N_{r}\right)$ can be calculated with the gamma spectrometry detected results of filter paper measured: 


$$
N_{r}=\frac{N_{d}}{\epsilon_{d} p_{\gamma}}
$$

Where $N_{d}$ is area under the photopeak, $\varepsilon_{d}$ is photopeak detection efficiency and $P_{\gamma}$ is the $\gamma$-ray emission probability

The complete process was described in (Martinez, J.E., et al 2017).

Detected decays by spectrometry really correspond to the difference between the not decayed nuclei after the transport time $t=t_{t}$ and not decayed nuclei after the time of measurement $t=t_{t}+t_{m}$ Eq.(8):

$$
N_{r}=N^{\prime}\left(t=t_{t}\right)-N^{\prime}\left(t=t_{t}+t_{m}\right)
$$

Where $N^{\prime}$ are the solutions of the second system of the differential equations.

According to this, the $\mathrm{Pb}-214$ detected decays are given by Eq.(9):

$N_{r}(P b-214)=e^{-\lambda_{P b} t_{t}}\left[1-e^{-\lambda_{P b} t_{m}}\right]\left[N_{P b}^{\prime}(0)-\frac{\lambda_{P o}}{\lambda_{P b}-\lambda_{P O}} N_{P o}^{\prime}(0)\right]+\frac{\lambda_{P o}}{\lambda_{P b}-\lambda_{P o}} N_{P o}^{\prime}(0) e^{-\lambda_{P o} t_{t}}\left[1-e^{-\lambda_{P o} t_{m}}\right]$

In this equation, $N^{\prime}{ }_{P o}$ is negligible because $e^{-\lambda_{P o}} \approx 0$, due to the large transport time. The $\mathrm{Bi}-214$ detected decays are given by Eq.(10).

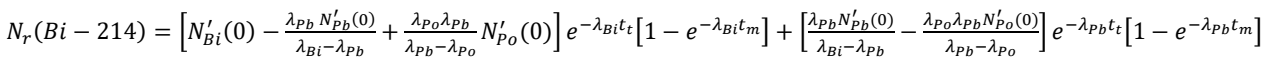

If $N_{P o}^{\prime}(0)$ and $N_{P b}^{\prime}(0)$ were known, it would be possible to obtain $N_{B i}^{\prime}(0)$, but, as we have said before $N_{P o}^{\prime}(0)$ is not possible to know, therefore the authors make this approximation:

$$
C_{P o}=F \frac{C_{A}(R n-222)}{\lambda_{P o}}
$$

Being $F$ an initial equilibrium factor estimated and $C_{A}(R n-222)$ the activity concentration of radon measured with the alfa spectrometer RAD7. Substituting the results into the previous equations and its results into the solution of the first differential equations system, the activity concentration of Bi-214 and $\mathrm{Pb}-214$ was obtained. Knowing the following equations:

$$
\begin{gathered}
E E C_{R n-222}=0.105 C_{A P o-218}+0.515 C_{A P o-214}+0.38 C_{A B i-214} \\
F=\frac{E E C_{R n-222}}{C_{A m}} \text { (13) }
\end{gathered}
$$

A new equilibrium factor is obtained. The value of $F$ obtained is introduced into Eq.(11) and the process is repeated, until the convergence.

\subsection{Compartment models}

In different ICRP publications the biokinetics models were developed. The biokinetics models describe the mechanism of deposition, absorption and elimination of the radioactive substances. The applications of these publications are diverse; the main application is for radiophysics and radiological protection purposes. These publications (ICRP,1994) and (ICRP 1997), describe the different organs of the human body as compartments. These compartments have inputs and outputs and they have different biokinetic models. All the biokinetic models are represented by a system of ordinary linear differential equations with constant coefficients (Sanchez, G. et al., 2006).

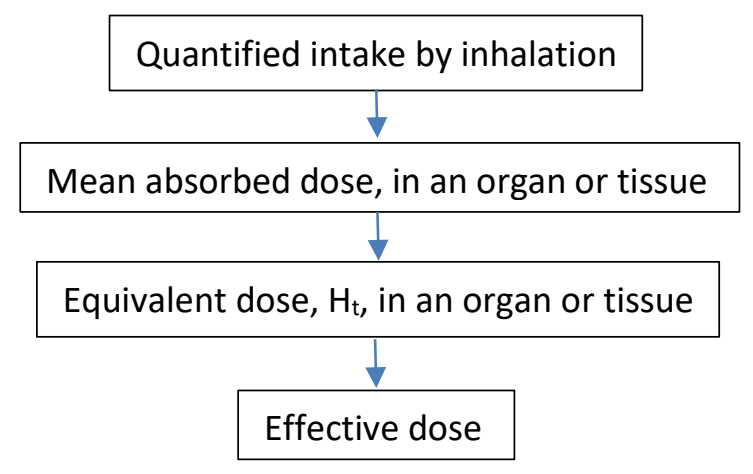


Figure 2. Effective dose determination.

The Eq. (14) represents in matrix form this system of ordinary linear differential equations with constant coefficients, where $k_{i j}$ represents the rate of inputs and outputs. The matrix $A$ is the compartment matrix and its diagonal elements are negative. The sum of all columns are zero. $q_{i}(t)$ represents the retention of the compartment $i$ and $b_{i}(t)$ represents an external input.

$$
\begin{gathered}
\frac{d}{d t} q(t)=A q(t)+b(t) \quad(14) \\
A=\left(\begin{array}{cccccc}
-k_{1} & k_{2,1} & \cdots & k_{n, 1} & 0 \\
k_{1,2} & -k_{2} & \cdots & k_{n, 2} & 0 \\
\cdots & \cdots & \cdots & \cdots & \cdots \\
k_{1, n} & k_{2, n} & \cdots & -k_{n} & 0 \\
k_{1, n+1} & k_{2, n+1} & \cdots & k_{n, n+1} & 0
\end{array}\right), b(t)=\left[\begin{array}{c}
b_{1}(t) \\
b_{2}(t) \\
\cdots \\
b_{n}(t) \\
0
\end{array}\right], q(t)=\left[\begin{array}{c}
q_{1}(t) \\
q_{2}(t) \\
\cdots \\
q_{n}(t) \\
0
\end{array}\right]
\end{gathered}
$$

The solution of this system is an ordinary linear differential equation, given an initial value $q_{0}$ :

$$
q(t)=e^{t A} q_{0}+\int_{0}^{t} e^{(t-\tau) A} b(\tau) d \tau
$$

Matrix $A$ have to be diagonalizable with real eigenvalues, therefore:

$$
e^{t A}=S e^{t \Lambda} S^{-1}
$$

So, equation 14 can be expressed as:

$$
q(t)=\sum_{i=1}^{n+1} S^{-1} q_{0} e_{i} e^{\lambda_{i} t}+S \int_{0}^{t} e^{(t-\tau) \Lambda} S^{-1} b(\tau) d \tau
$$

Where $\Lambda$ is the diagonal matrix of eigenvalues and $S$ is the matrix of eigenvectors.

\subsection{Human Respiratory Tract}

The ICRP 66 (ICRP, 1994) and 78 (ICRP, 1997) describes the Human Respiratory Tract and Internal Expose for Workers. The inhalation can be divided into two process: deposition and elimination. Deposition is the process that determines what fraction of the inspired particles is caught in the respiratory tract and, thus, fails to exit with expired air. It is likely that all particles that touch a wet surface are deposited; thus, the site of contact is the site of initial deposition.

The response to the alpha energy produced by radon progeny depends not only on the amount of aerosol deposited but also on the amount retained in the lungs over time. Retention is the amount of material present in the lungs at any time and equals deposition minus clearance. An equilibrium concentration is reached during continuous exposure to radon progeny when the rate of deposition equals the rate of clearance. The amount of particles retained within a specific lung region over time is a key determinant of dose.

The behavior of a particle in the respiratory system is largely determined by its size and density. Particles of varying shape and density may be compared by their aerodynamic equivalent diameter (ADAM).

\subsubsection{Deposition calculation}


The extent to which each mechanism contributes to the deposition of a specific particle depends on the particle's physical characteristics, the subject's breathing pattern, and the geometry of the respiratory tract. To model the particle deposition, the regions were treated as a series of filters in ICRP66, during both inhalation and exhalation. The efficiency of each was evaluated by considering aerodynamic (gravitational settling, inertial impaction) and thermodynamic (diffusion) processes acting competitively.

The air flow will go through these filters both at inhalation and exhalation. With this method we get the fractions referred to the deposition for each of the compartments (ET1, ET2, BB, bb, AI).

The authors follow the recommendation of the ICRP 66 (ICRP,1994) for the calculation for the IDF'S (Initial Deposition Fractions).

\subsubsection{Elimination calculation (transport and absorption into blood)}

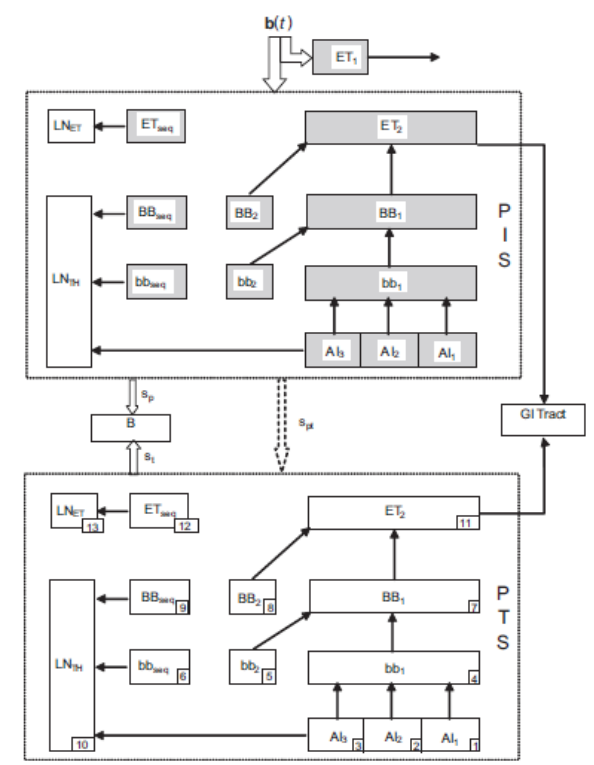

Figure 3. Human Respiratory Tract Model. $\mathrm{ET}_{1}$ and $\mathrm{ET}_{2}$ are the Extrathoracic Region (nose, mouth, larynx and pharynx), BB is the Bronchial Region, bb is the Bronchiolar Region, AI is the Alveolar-Interstitial Region and $\mathrm{LN}_{\mathrm{ET}}, \mathrm{LN}_{\mathrm{TH}}$ are lymphatics nodes (ICRP, 1994).

In the Figure 3 dark compartments are the initial deposition. The black arrows are the directions of the mechanical particle transport to stomach and lymphatics nodes. In the PIS (Particles in Initial State) particles are deposited firstly and they are absorbed into blood at an absorption rate $s_{p}$. At the same time, they are transferred from PIS to PTS (Particles in Transform State) at a rate $s_{p t}$. Also the particles in PTS are absorbed into blood at an absorption rate $s_{t}$.

The absorption rates $\left(s_{p}, s_{p t}\right.$ and $\left.s_{t}\right)$ depend on the chemical form of the elements. These absorption rates can be of three kinds of rates, $\mathrm{F}$ fast, $\mathrm{M}$ moderate and $\mathrm{S}$ slow.

The system PIS can be represented with $A_{l}$ matrix and the retention can be calculating with:

$$
q_{A 1}(t)=I_{0} I D F e^{t A_{1}}
$$

The system PTS can be represented with $A_{2}$ matrix and the retention can be calculated with:

$$
q_{A 2}(t)=\operatorname{spt} \int_{0}^{t} e^{(t-\tau) A_{2}} q_{A_{1}}(\tau) d \tau
$$

Therefore, the retention of the total Human Respiratory Tract is calculated with:

$$
q_{A}(t)=q_{A 1}(t)+q_{A 2}(t)
$$

\subsubsection{Equivalent dose}


To calculate the equivalent dose, the radioactive decay has to be added to retention

$$
x_{s, i}(t)=q_{s, i}(t) e^{-\lambda_{i}}
$$

Integration is used to find the total number of disintegrations:

$$
U_{s, i}(\tau)=\int_{0}^{\tau} x_{i}(t) d t
$$

$U_{s, i}$ is the total number of nuclear transforms of radionuclide $i$, of the decay chain in the source region $S$. Keeping in mind that the $\mathrm{SEE}(\mathrm{T} \leftarrow \mathrm{S}$ ) ( is the total energy absorbed per unit mass in the target $\mathrm{T}$ due to organ $\mathrm{S}$ and radionuclide $i \mathrm{~Sv} / \mathrm{Bq} \mathrm{s}^{-1}$ )

$$
S E E(T \leftarrow S)_{i}=1.6 \cdot 10^{-13} \frac{1}{m_{T}} \sum_{R} Y_{R} E_{R} w_{R} A F(T \leftarrow S)_{R}
$$

- $\quad Y_{R}=$ is the yield of radiation $\mathrm{R}$ per nuclear transformation for radionuclide $i$.

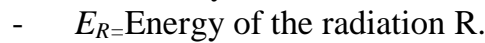

- $\quad w_{r}$ is the weighting factor for radiation $\mathrm{R}$ emitted in $\mathrm{S}$.

- $A F(T \leftarrow S)_{R}=$ is the fraction of the energy of radiation E emitted in $\mathrm{S}$

- $\quad m_{T}=$ is the mass of the target tissue.

Therefore:

$$
\begin{gathered}
H_{T}(t)=\sum_{i, s} U_{s, i}(\tau) S E E(T \leftarrow S)_{i} \\
H_{t}(t)=\sum_{T} w_{T} H_{T}(t)
\end{gathered}
$$

Where $w_{i}$ is the weighting factors assigned for the partition of radiation detriment among respiratory tract tissues ICRP 66 (ICRP,1994) $H_{T(t)}$ are the equivalent doses in the HRT model $\left(\mathrm{ET}_{1}, \mathrm{ET}_{2}, \mathrm{LN}_{\mathrm{ET}}, \mathrm{BB}_{\text {basal }}\right.$, $\mathrm{BB}_{\mathrm{sec}}$, bb and $\mathrm{AI}$ ), and $H_{t}(t)$ are the equivalent doses in the two organs of the respiratory tract, (lungs, extrathoracic airways).

Finally, to obtain the effective dose it has to take into account the weighting factors published in the ICRP 103 (ICRP, 2007) for lungs and extrathoracic airways, 0.21 and 0.001 respectively.

\section{Results and validation}

\subsection{Equilibrium factor determination}

In order to check our methodology, firstly, the algorithm was applied to measurements obtained by Forkapić, S (Forkapić, S., 2011). The equilibrium factor obtained with our methodology was $F=0.55$, which was in good agreement with the equilibrium factor obtained by Forkapic in his work $F=0.56$.

Keeping in mind that the half-life of radionuclides are Po-218 (3.1 min), Pb-214 (26.8 min) y Bi-214 (19.8 min). The measure was made with $1000 \mathrm{~s}$ duration. The next table displays the obtained results. The net areas under the photopeaks of $351.9 \mathrm{keV}(\mathrm{Pb}-214)$ and $609.3 \mathrm{keV}(\mathrm{Bi}-214)$ obtained experimentally are listed. The measurement of Po-218 are null.

Table.1: Results of the measurements of the gamma spectrometry

\begin{tabular}{rl|c|c|c|c|}
\hline $\mathrm{t}_{\mathrm{t}}(\mathrm{s})$ & $\mathrm{t}_{\mathrm{m}}(\mathrm{s})$ & $\mathrm{t}_{\mathrm{t}}+\mathrm{t}_{\mathrm{m}}(\mathrm{s})$ & $\mathrm{Pb}-214^{*}$ & $\mathrm{Bi}-214^{* *}$ \\
\hline 7200 & 1000 & 8200 & 224 & 303 \\
\hline \multicolumn{4}{|c|}{$* \mathrm{Nd}(351.9 \mathrm{keV}) \varepsilon \mathrm{d}=0.092275 \quad \mathrm{p} \gamma=0.371$} \\
& $* * \mathrm{Nd}(609.3 \mathrm{keV}) \varepsilon \mathrm{d}=0.0557879 \quad \mathrm{p} \gamma=0.461$
\end{tabular}


According to radon concentration (it was measured with alpha spectrometry) in air it was $\mathrm{C}_{\mathrm{Rn}}-222=368 \pm 6$ $\mathrm{Bq} / \mathrm{m}^{3}$, and the equilibrium factor, calculated with our methodology, between radon and its progeny was $F=0.27$. With this equilibrium factor and substituting in Eq.(6), the authors obtain the following results:

$$
\begin{aligned}
C_{A}(P o-218) & =\lambda_{P o} C_{P o}=104.2 \frac{\mathrm{Bq}}{\mathrm{m}^{3}} \\
C_{A}(P b-214)=\lambda_{P b} C_{P b} & =161.4 \frac{\mathrm{Bq}}{\mathrm{m}^{3}} \\
C_{A}(B i-214)=\lambda_{B i} C_{B i} & =32.6 \frac{\mathrm{Bq}}{\mathrm{m}^{3}}
\end{aligned}
$$

The $\mathrm{C}_{\mathrm{A}}$ of the Po-214 is the same of the Bi-214 because the period of Po-214 is $164.3 \mu \mathrm{S}$ as the authors said before.

\subsection{Conversion dose factors}

In order to obtain the dose conversion factor, the authors have developed an algorithm following the ICRP 66 (ICRP, 1994) indications in the HRT. The results obtained were compared with the program LUDEP 2.0 (Jarvis N, 1996). For each short life progeny of the radon, an acute inhalation of $1 \mathrm{~Bq}$ and fast absorption F were introduced into the software UPVDose.

\begin{tabular}{|c|c|c|c|c|c|c|c|c|}
\hline \multicolumn{3}{|c|}{ Rapid absorption F Po-218 } & \multicolumn{3}{|c|}{ Rapid absorption F Pb-214 } & \multicolumn{3}{|c|}{ Rapid absorption F Bi-214 } \\
\hline & $\begin{array}{l}\text { UPVDose } \\
\text { (Sv/Bq) }\end{array}$ & $\begin{array}{c}\text { LUDEP } 2.0 \\
(\mathrm{~Sv} / \mathrm{Bq})\end{array}$ & & $\begin{array}{l}\text { UPVDose } \\
\text { (Sv/Bq) }\end{array}$ & $\begin{array}{c}\text { LUDEP } 2.0 \\
(\mathrm{~Sv} / \mathrm{Bq})\end{array}$ & & $\begin{array}{l}\text { UPVDos } \\
\text { e (Sv/Bq) }\end{array}$ & $\begin{array}{c}\text { LUDEP } 2.0 \\
(\mathrm{~Sv} / \mathrm{Bq})\end{array}$ \\
\hline ET1 & $1.42 \mathrm{E}-09$ & $1.40 \mathrm{E}-09$ & ET1 & $4.83 \mathrm{E}-11$ & $4.70 \mathrm{E}-11$ & ET1 & $3.62 \mathrm{E}-11$ & $3.50 \mathrm{E}-11$ \\
\hline ET2 & $7.29 \mathrm{E}-09$ & 7.32E-09 & ET2 & $2.85 \mathrm{E}-10$ & $2.80 \mathrm{E}-10$ & ET2 & $2.72 \mathrm{E}-10$ & $2.70 \mathrm{E}-10$ \\
\hline $\mathbf{L N}_{\mathrm{ET}}$ & 1.23E-19 & $4.90 \mathrm{E}-19$ & $\mathbf{L N}_{\mathbf{E T}}$ & $2.13 \mathrm{E}-21$ & $2.10 \mathrm{E}-18$ & $\mathbf{L N}_{\mathbf{E T}}$ & $5.23 \mathrm{E}-21$ & $5.50 \mathrm{E}-18$ \\
\hline $\mathbf{B B}_{\text {basal }}$ & $3.11 \mathrm{E}-10$ & $3.08 \mathrm{E}-10$ & $\mathbf{B B}_{\text {basal }}$ & $7.07 \mathrm{E}-12$ & $7.06 \mathrm{E}-12$ & $\mathbf{B B}_{\text {basal }}$ & $6.65 \mathrm{E}-12$ & $6.55 \mathrm{E}-12$ \\
\hline $\mathbf{B B}_{\text {sec }}$ & 3.41E-09 & $3.37 \mathrm{E}-09$ & $\mathbf{B B}_{\text {sec }}$ & $8.69 \mathrm{E}-12$ & $8.49 \mathrm{E}-12$ & $\mathbf{B B}_{\text {sec }}$ & $7.57 \mathrm{E}-12$ & $7.49 \mathrm{E}-12$ \\
\hline bb & $1.18 \mathrm{E}-09$ & $1.57 \mathrm{E}-09$ & bb & $1.69 \mathrm{E}-12$ & $1.57 \mathrm{E}-12$ & bb & $1.96 \mathrm{E}-12$ & $2.03 \mathrm{E}-12$ \\
\hline AI & $6.37 \mathrm{E}-11$ & $6.29 \mathrm{E}-11$ & AI & $3.53 \mathrm{E}-13$ & $3.66 \mathrm{E}-13$ & AI & $9.51 \mathrm{E}-13$ & $9.32 \mathrm{E}-13$ \\
\hline $\mathbf{L N}_{\mathrm{TH}}$ & $1.31 \mathrm{E}-18$ & $1.29 \mathrm{E}-18$ & $\mathbf{L N}_{\mathrm{TH}}$ & $2.26 \mathrm{E}-20$ & $1.00 \mathrm{E}-17$ & $\mathbf{L N}_{\mathrm{TH}}$ & $5.56 \mathrm{E}-20$ & $2.80 \mathrm{E}-17$ \\
\hline
\end{tabular}

Table.2: Results of the comparison between UPVDose and LUDEP 2.0 (equivalent dose). $1 \mathrm{~Bq}$ and Acute Inhalation.

In Table 2, the doses calculated for Bi-214 are only for the beta disintegration, as the Po-214 has a tiny period it can be said that the $\mathrm{Bi}-214$ has a double disintegration alpha and beta. In view of the above, the equivalent doses were recalculated. The new results are show in the Table 3.

Table.3: Results of the Bi-214 with double disintegration.

\begin{tabular}{|c|c|}
\hline & $(\mathrm{Sv} / \mathrm{Bq})$ \\
\hline ET1 & $6.38 \mathrm{E}-08$ \\
\hline ET2 & $3.23 \mathrm{E}-07$ \\
\hline LN $_{\text {ET }}$ & $1.53 \mathrm{E}-18$ \\
\hline BB $_{\text {basal }}$ & $1.06 \mathrm{E}-08$ \\
\hline BB $_{\text {sec }}$ & $2.01 \mathrm{E}-08$ \\
\hline $\mathbf{b b}$ & $4.60 \mathrm{E}-09$ \\
\hline $\mathbf{A I}$ & $2.79 \mathrm{E}-10$ \\
\hline $\mathbf{L N}_{\mathrm{TH}}$ & $1.63 \mathrm{E}-17$ \\
\hline
\end{tabular}

Considering the recommendations of the ICRP 66 (ICRP, 1994) and the ICRP 103 (ICRP, 2007) for the tissue weighting factors, the authors have calculated the effective doses.

Table.4: Results of effective dose for each radionuclide, in the human respiratory tract per $1 \mathrm{~Bq}$ of intake.

\begin{tabular}{|c|c|c|}
\hline \multicolumn{3}{|c|}{ Effective dose (Sv/Bq) } \\
\hline Po-218 & Pb-214 & Bi-214 \\
\hline $6.83 \mathrm{E}-10$ & $5.47 \mathrm{E}-12$ & $8.13 \mathrm{E}-09$ \\
\hline
\end{tabular}

The results for the effective dose of $\mathrm{Pb}-214$ and $\mathrm{Bi}-214$ can be compared with the effective dose published on ICRP 119 (ICRP, 2012). In this publication, the effective dose for $\mathrm{Pb}-214$ and $\mathrm{Bi}-214$ are $4.8 \cdot 10^{-9} \mathrm{~Sv} / \mathrm{Bq}$ and $1.2 \cdot 10^{-8} \mathrm{~Sv} / \mathrm{Bq}$ respectively. These differences are because in ours, calculations only beta and alpha are present, while in the ICRP also the gamma radiation, and the gastrointestinal tract are considered. All this 
methodology was applied for an aerosol with $5 \mu \mathrm{m}$ of AMAD, $\sigma_{\mathrm{g}}=2.5$, particle density $\rho=3 \mathrm{~g} \mathrm{~cm}-3$ and shape factor of $\chi=1.5$. The subject of this work is a worker with light exercise ventilation rate $1.2 \mathrm{~m}^{3} \mathrm{~h}^{-1}$ (recommendation of ICRP), working 480 hours per year. In Tables 4 and 5 the authors present the results for the effective doses for each worker in the human respiratory tract.

Table.5: Results of effective dose for each radionuclide (Rapid absorption).

\begin{tabular}{|c|c|c|c|}
\hline \multicolumn{4}{|c|}{ Effective dose per year } \\
\hline Po-218 & Pb-214 & Bi-214 & Total \\
\hline $34.2 \mu \mathrm{Sv}$ & $0.42 \mu \mathrm{Sv}$ & $127 \mu \mathrm{Sv}$ & $\mathbf{1 6 2} \boldsymbol{\mu S v}$ \\
\hline
\end{tabular}

The authors repeated the same calculations for moderate absorption of Po-218, and Bi-214 and results for effective dose per year and worker are presented in Table 6.

Table.6: Results of effective dose moderate absorption Po and Bi.

\begin{tabular}{|c|c|c|c|}
\hline \multicolumn{4}{|c|}{ Effective dose per year } \\
\hline Po-218 & Pb-214 & Bi-214 & Total \\
\hline $51.3 \mu \mathrm{Sv}$ & $0.42 \mu \mathrm{Sv}$ & $268 \mu \mathrm{Sv}$ & $\mathbf{3 1 9} \boldsymbol{\mu S v}$ \\
\hline
\end{tabular}

Following the indications of the ICRP, the authors calculated the effective doses for $\mathrm{Pb}-214$ and $\mathrm{Bi}-214$ The Po-218 it is not present at the list published by the ICRP, the results, are presented in Table 7.

Table.7: Results of effective dose moderate absorption and fast according to ICRP values for each radionuclide.

\begin{tabular}{|c|c|c|}
\hline & Effective dose (ICRP) (Sv/Bq) & Effective dose per year \\
\hline Pb-214 & $4.80 \mathrm{E}-09$ & $317 \mu \mathrm{Sv}$ \\
\hline Bi-214 (fast absorption) & $1.20 \mathrm{E}-08$ & $184 \mu \mathrm{Sv}$ \\
\hline Bi-214 (moderate absorption) & $2.10 \mathrm{E}-08$ & $3.23 \mu \mathrm{Sv}$ \\
\hline
\end{tabular}

The sum of the effective doses per year and worker are presented in Table 8.

Table 8. Sum of effective doses.

\begin{tabular}{|c|c|}
\hline & Total dose per year \\
\hline Fast & $\mathbf{5 5 5} \boldsymbol{\mu S v}$ \\
\hline Moderate & $\mathbf{6 9 4} \boldsymbol{\mu S \mathrm { Sv }}$ \\
\hline
\end{tabular}

\section{Conclusions}

The measure of the Po-218 is not possible if the distance between sampling and the laboratory of the measurement is great, due to its short period. In this work, this trouble is resolved with a new methodology. The low doses received by workers are due to the limited working hours stablished in a year for them, and the low equilibrium factor is due to the air extraction system of the WWTP, which renews the air 10 times per hour.

The effective doses calculated using UPVDose are in a good agreement with the results published in the ICRP 119 (ICRP, 2012) and the one obtained using LUDEP 2.0. Other important parameter in dose calculations is the kind of absorption of the radionuclide. In our case, if the absorption is fast the effective dose in HRT is $162 \mu \mathrm{Sv}$ per year while if the absorption is moderate the effective dose is $319 \mu \mathrm{Sv}$ per year. For exposures to radon (222Rn) gas, inhalation of their short-lived decay products generally gives much higher contributions to effective dose than inhalation of the gas itself. Following inhalation of the shortlived progeny most of their decay takes place in the lung before clearance can occur, either by absorption into blood or by particle transport to the alimentary tract. As a consequence, the lung dose contributes around $90 \%$ of the effective dose for the pair $\mathrm{Bi}-214 / \mathrm{Po}-214$, while for the $\mathrm{Pb}-214$, the human gastrointestinal tract is more important. Moreover, ICRP model does not take into account Po-218 contribution, while our model calculates inhalation effective dose considering the effect of this radionuclide. 


\section{Bibliography}

Durridge Radon Instrumentation, 2015. RAD 7 Radon Detector, user manual. DURRIDGE Company https://durridge.com/products/rad7-radon-detector/.

Forkapić, S., Mrđa, D., Vesković, M., Todorović, N., Bikit, K., Nikolov, J., Hansman, J., 2012. . Radon equilibrium measurement in the air. In: Paper presented at the First East European Radon Symposium-FERAS.

ICRP, 1993. Protection Against Radon-222 at Home and at Work. ICRP Publication 65. Ann. ICRP 23 (2).

ICRP, 1994. Human Respiratory Tract Model for Radiological Protection. ICRP Publication 66. Ann. ICRP 24 (1-3).

ICRP, 1997. Individual Monitoring for Internal Exposure of Workers. ICRP Publication 78. Ann. ICRP 27 (3-4).

ICRP, 2007. The 2007 Recommendations of the International Commission on Radiological Protection. ICRP Publication 103. Ann. ICRP 37 (2-4).

ICRP, 2012. Compendium of Dose Coefficients based on ICRP Publication 60. ICRP Publication 119. Ann. ICRP 41(Suppl.)

Hongyu Zhu et al 2018., Establishment of detailed respiratory tract model and Monte Carlo simulation of radon progeny caused dose. J. Radiol. Prot. 38990.

Jarvis, N.; Birchall, A.; James, A.; Bailey, M.; Dorrian., 1996. M. LUDEP 2.0: Personal computer program for calculating internal doses using the ICRP Publication 66 respiratory tract model; Technical Report NRPB-SR287; NRPB: Chilton, UK.

Marsh, James W., Laurier, Dominique., Tirmarche, Margot., 2017. Radon dosimetry for workers ICRP's approach. Radiation Protection Dosimetry. http://dx.doi.org/10.1093/rpd/ncx065.

Martinez, J.E., Juste, B., Ortiz, J., Martorell, S., Verdu, G., 2016. Air radon equilibrium factor measurement in a Waste Water PreTreatment Plant. Radiation Physics and Chemistry. https://doi.org/10.1016/j.radphyschem.2017.03.011

Ramola, R. C., Prasad, M., Kandari, T., Pant, P., Bossew, P., Mishra, R., \& Tokonami, S. 2016. Dose estimation derived from the exposure to radon, thoron and their progeny in the indoor environment. Scientific Reports, 6, 31061. http://doi.org/10.1038/srep31061 Sánchez, G., Rodríguez-Díaz, J. M.; 2007. Optimal design and mathematical model applied to establish bioassay programs. Radiat Prot Dosimetry 2007; 123 (4): 457-463. doi: 10.1093/rpd/ncl499 